NEWS

\title{
Ukraine scientists grow impatient for change
}

Ukraine's 'orange revolution' - a national protest against corruption that overthrew the first results of the country's 2004 election raised hopes for political and societal change. But more than a year on, scientists are increasingly frustrated by the slow pace of reform of the country's Soviet-style research system, which they believe is being hampered by Ukraine's aged and anti-European scientific establishment.

The nation, which has a "Nothing will change population of 48 million and is in Ukrainian science Europe's second-largest coun- as long as the current try in terms of area, has a long tradition in science and hosts system exists."
28,000 researchers. The powerful academy, a relic of the Soviet science complex, dominates Ukrainian science. The average age of the academicians is about 71; the president, Boris Paton, an expert in electric welding and the son of the former president, is 85 .

The bulk of the academy's activities relate to mechanics, material sciences and physics euphemisms, according to critics, for former military-oriented engineering institutes. And productivity is low. According to the Thomson Scientific (ISI) statistics, academy scientists publish around 1,500 papers a year - roughly one-third of the output of Britain's University of Manchester alone.

But critics say the academy is not interested in carrying out an independent review of its scientific performance. There are also claims of widespread corruption. For example, an attempt to create closer ties between Ukraine and western European institutions by linking Ukraine to GÉANT, the high-speed European data communication network, was allegedly hindered by academy members demanding bribes. Another complaint is that the academy leaders, fearing competition and loss of influence, are blocking attempts to facilitate Ukraine's participation in research pro-

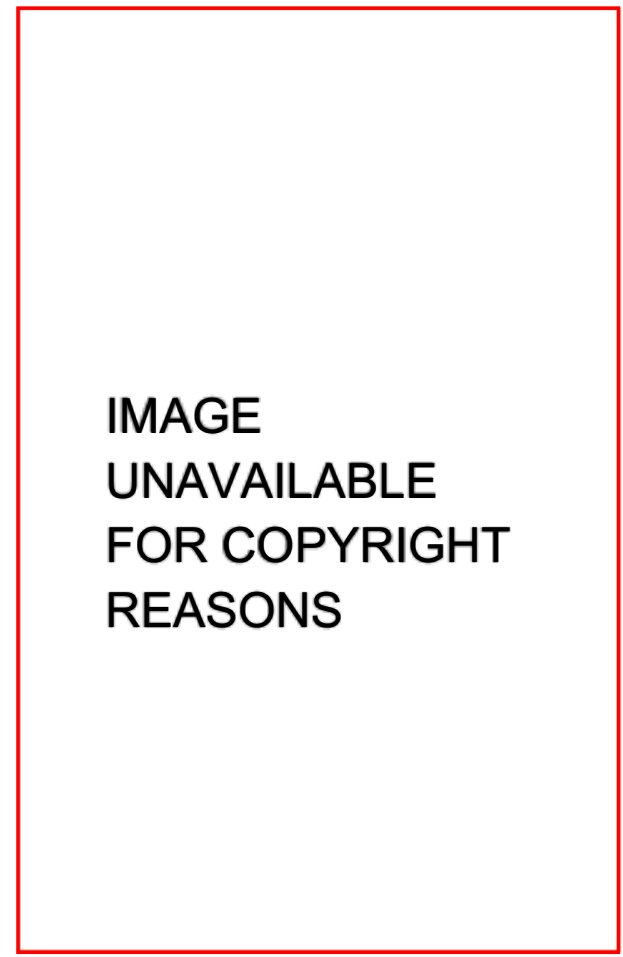

Russian premier Vladimir Putin (left) salutes academy president Boris Paton, aged 85.

grammes funded by the European Union (EU), by deliberately holding back information and generally failing to cooperate with EU authorities.

"The Academy is not interested in any reform whatsoever," says Aleksei Boyarski, a theoretical physicist at CERN, the European lab for particle physics in Geneva, Switzerland.

\section{Evidence for bubble fusion called into question}

ONLINE SPECIAL REPORT

Fresh questions surround the claims that bubble fusion has been achieved, according to an investigation by Nature.

Reports by Rusi Taleyarkhan that he hadachieved table-top fusion in collapsing bubbles caused a storm when they were published in $\mathbf{2 0 0 2}$ (R.P.Taleyarkhan et al. Science 295, 1868-1873; 2002).

Taleyarkhan, a nuclear engineer now basedat Purdue University in West Lafayette, Indiana, used sound waves to cause the formation and collapse of bubbles within a liquid. The conditions inside the collapsing bubbles are theoretically extreme enough to allow nuclear fusion to take place. Taleyarkhanclaims to have achieved this - aneffect that, if real, could one day provide an almostlimitless source of energy.

Four years later, Taleyarkhan's work retains analmost magical ability tograb the headlines, most recently in January, when hislatest results (R.P. Taleyarkhan et al. Phys. Rev. Lett. 96, 034301; 2006) were promotedina press release by the American Physical Society. Millions of dollars are being spent trying to repeat the work, including $\$ 800,000$ from the US Department of Defense.

But corroboration remains elusive. Now, an investigation into the circumstances surrounding Taleyarkhan's experiments is throwing up serious questions about the validity of the work.

Interviews with researchers who have worked closely with Taleyarkhan at Purdue reveal concerns abouthis actions since he arrived there full-time in 2004. The steps he has taken, they say, include claiming he obtained positive results from equipment on which they had seen only negative data, and removing the equipment from their lab altogether.

And physicist Brian Naranjo of the University of California, Los Angeles, has completed an analysis that he plans to post later this week on arXiv. It suggests that the spectrum reported in Taleyarkhan's latest paper as proof of nuclear fusioncame instead from the radioactive decay of a standardlab material.

Taleyarkhan has declined to comment on eventsat Purdue, or on Naranjo's analysis, and he vigorously affirms that his results are validand the effect is real. But the overall message frompeople close to this work is that there is little hope this particularapproach willyield a viable fusion energy source. Eugenie Samuel Reich For the full investigation please see inwwuature.com/news/bubblefusion 
IMAGE

\section{UNAVAILABLE} FOR COPYRIGHT REASONS

"Nothing will change in Ukrainian science as long as this system exists."

Ukrainian scientists are eligible for EU research money thanks to a 2002 association agreement with the European Commission's framework programme for research. But so far, only seven out of thousands of EU-funded projects include Ukrainian participants, says Vadym Yashenkov, deputy director of Ukraine's National Information Point for EU research.

According to Yashenkov, this is partly because of the general weakness of Ukrainian science and industry, and the complicated application procedures that put off many scientists.

But participation is also hindered because the academy fails to provide and disseminate relevant documents and information, says Oleh Napov, a science attaché at the Ukrainian mission to the EU in Brussels, Belgium. For example, Napov has submitted a proposal for scientific reform to the Ukrainian research ministry. He says that when he asked the academy to outline its scientific priorities, he received only a list of the names and titles of all current academicians, and a letter stating that the academicians themselves were the academy's priorities.

${ }^{\alpha}$ Maybe they have not asked us in a proper way, counters Yaroslav Yatskiv, director of the Main Astronomical Observatory in Kiev, and a member of the academy's presidium. The president, Paton, had not responded to queries when Nature went to press.
Yatskiv says he is aware that corruption is a widespread problem within the academy. ${ }^{\text {cIt }}$ is true, unfortunately, that funding is not based on scientific merit, ${ }^{n}$ he says. But he adds that efforts to evaluate and possibly transform the academy are being considered.

\section{Braindrain}

Yatskiv has recently proposed the creation of a National Science Foundation that, like its US counterpart, would fund research on the sole basis of excellence judged by peer review. But Paton last year told a presidium meeting that the future role of the academy should be similar to that of the Siberian branch of the Russian Academy of Sciences, another relic of the Soviet science complex. "I don't think this is a good idea," says Yatskiv.

Resistance to the academy's backward-looking plans is growing, both inside and outside Ukraine. A 13-strong group of Ukrainian scientists, led by Boyarski, has suggested to the country's science ministry a detailed concept of domestic reform, including rigorous evaluation of all academy institutes, the creation of an international institute of advanced study in Kiev and of a number of centres of excellence supported by the EU.

${ }^{\alpha}$ Things back home really need to improve substantially," says Alexej Verkhratsky, a Ukrainian-born neurophysiologist at the University of Manchester and a member of Boyarski's group. "If they don't, our best young people will soon have left for good. A considerable number of Ukrainian scientists working abroad (myself included) would come back if things were reorganized."

${ }^{\alpha}$ We have the same potential, scientifically and politically, as Poland or Hungary to become a genuine part of Europe," adds Oleg Krishtal, deputy director of the academy's Bogomoletz institute of physiology in Kiev.

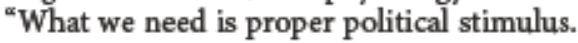
Clearly, the academy cannot repair itself as long as the old guard is keeping all the key positions."

Christian Patermann, director for biotechnology, agriculture and food at the European commission's directorate general for research in Brussels, led an EU delegation to Ukraine last month. He says that the country's scientific potential in areas such as materials sciences, energy, space and organic farming is impressive and deserves European support. Patermannn is optimistic that the academy will not ultimately stand in the way of reform. "The Czech Republic, Hungary and the Baltic countries have all managed to reform their academies of science; sooner or later this will also happen in Ukraine." Seealso page 128.

Quirin Schiermeier
ON THE RECORD

"Mars is hard, and Mars is unpredictable. Mars doesn't treat you very well."

NASA's Jim Graf crosses his fingers for the Mars Reconnaissance Orbiter spacecraft, due to arrive at the red planet on 10 March.

\section{'Libertines, both male and female, have always been around in math and physics."}

Science writer Jennifer Ouellette ponders whether physicists are really having more sex these days.

Sources: Washington Post, Seed

\section{SCORECARD}

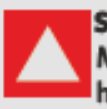

Science and lkung fu Movie star Jackie Chan has just secured himself a very different type of billing. The Australian NationalUniversity is naming a new science centre after the action hero as a vote of thanks for his recent donation.

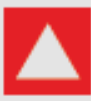
Waterfowl Researchers in Canada have come up with a way tostop wading birds landing on oil fields in Alberta. As the birds fly in, radar picks them up and triggers a deterrent noise.

$\wedge$ Perfume Japanese scientistshave found an unusual source of vanillin, the aromatic component of vanilla used as a fragrance. The sweetsmellcan, apparently, be extracted from cow dung.

\section{NUMBER CRUNCH}

A study by the US Centers for Disease Control and Prevention suggests that moving to the United States, especially if you are hispanic, might be bad for your health.

$16 \%$ of Hispanicimmigrants living in the UnitedStates for five years or less are obese.

$13 \%$ of the same group have high blood pressure.

$22 \%$ of Hispanic immigrants living in the UnitedStates for more than five years are obese.

$20 \%$ of the same group have high blood pressure. 